\title{
FIREDOC Users Manual, 3rd Edition
}

\author{
Nora H. Jason
}

Building and Fire Research Laboratory

Gaithersburg, Maryland 20899

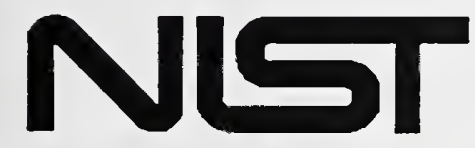

\section{Innited States Department of Commerce}

QC y Administration

QC nstitute of Standards and Technology

100

.456

110. 5305 


\title{
ERRATA
}

\section{FIREDOC USERS MANUAL, 3RD EDITION \\ NISTIR 5305 \\ Nora H. Jason \\ December 1993}

\author{
Building and Fire Research Laboratory \\ National Institute of Standards and Technology \\ Gaithersburg, MD 20899
}

PAGE 18, No. 2

In the "Disk File Name" field, you must now identify your file in the following format: FILES/FILENAME.LST

Therefore, in our example, the format would look like:

FILES/SMTH1.LST

This format will allow you to write this file to your hard disk. 


\section{FIREDOC Users Manual, 3rd Edition}

Nora H. Jason

December 1993

Building and Fire Research Laboratory

National Institute of Standards and Technology

Gaithersburg, MD 20899

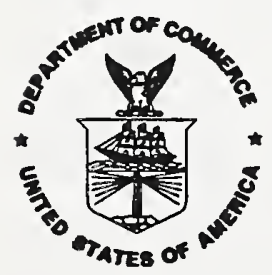

U.S. Department of Commerce

Ronald H. Brown, Secretary

Technology Administration

Mary L. Good, Under Secretary for Technology

National Institute of Standards and Technology Arati Prabhakar, Director 


\title{
ERRATA
}

\section{FIREDOC USERS MANUAL, 3RD EDITION}

\author{
NISTIR 5305 \\ Nora H. Jason \\ December 1993
}

Building and Fire Research Laboratory

National Institute of Standards and Technology

Gaithersburg, MD 20899

PAGE 18, No. 2

In the "Disk File Name" field, you must now identify your file (all lower case characters) in the following format:

$$
\text { files/filename.lst }
$$

Therefore, in our example, the format would look like:

$$
\text { files/smth1.lst }
$$

This format will allow you to write this file to your hard disk.

PAGE 19, No. 6

Please enter the file to clean: files/smth1.lst

Please enter name for cleaned file: files/smth $1 . t x t$

PAGE 35

1. Please enter the file to tvpe: files/smth $1 . t x t$

\section{PAGE 38}

userid for logging in on firedoc.cfr.nist.gov (file name)

password for logging in as $\mathrm{xxxxx}$ on firedoc.cfr.nist.gov ftp <Enter $>$

xxxxx (your FIREDOC ID) <Enter>

get files/filename OR get files/smth1.txt 



\section{.}


Contents

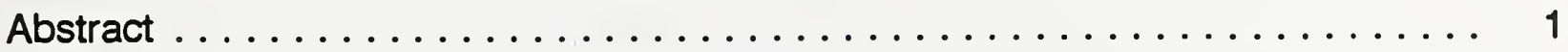

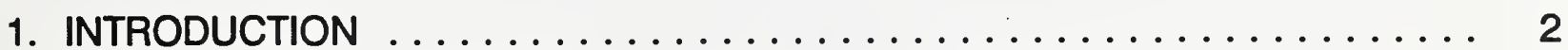

2. SELECTING A COMMUNICATIONS PACKAGE ............... 3

3. USING THE SEARCH PROGRAM $\ldots \ldots \ldots \ldots \ldots \ldots \ldots \ldots \ldots \ldots \ldots$

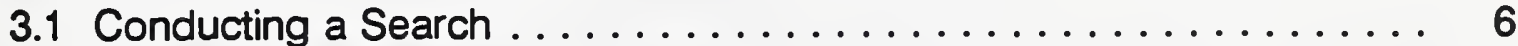

3.2 Searching Fields $\ldots \ldots \ldots \ldots \ldots \ldots \ldots \ldots \ldots \ldots . \ldots \ldots$

3.3 Using Boolean Operators and Parentheses .............. 9

3.4 Using Search Numbers in the Search Expression ... . . . . . . . . . . 11

3.5 Using Wildcard Characters in the Search Expression . . . . . . . . 11

3.5.1 Using Wildcard Characters in the Author Search . . . . . . . . . 12

3.6 Using the Command Line ....................... 12

3.7 Using the Index Feature . . . . . . . . . . . . . . . 13

3.8 Saving and Recalling Searches . . . . . . . . . . . . . 14

3.9 Displaying the Search Results . . . . . . . . . . . . . 15

3.10 Using the Options Command ................... 17

3.11 Obtaining Printed Copies of Search Results .............. 18

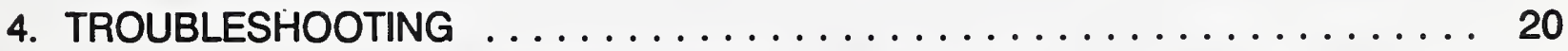

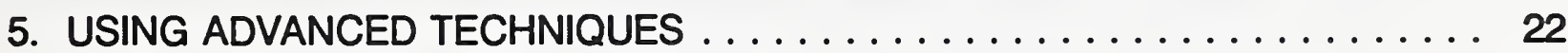

5.1 Advanced Searching Techniques ................. 22

5.2 Advanced Display/Print Techniques . . . . . . . . . . . . . 24

6. OBTAINING THE REFERENCES $\ldots \ldots \ldots \ldots \ldots \ldots \ldots \ldots \ldots$

7. ACKNOWLEDGEMENTS $\ldots \ldots \ldots \ldots \ldots \ldots \ldots \ldots \ldots \ldots \ldots$

8. BIBLIOGRAPHY ........................ 27

APPENDIX A: BOOLEAN OPERATORS. .................. 28

APPENDIX B: ABBREVIATIONS, COMMANDS, DISPLAY/PRINT FORMATS $\ldots \ldots 29$

APPENDIX C: DESIGNATION AND USE OF KEYS ON PC KEYBOARD . . . . . . 31

APPENDIX D: PROCOMM PLUS PROCEDURES $\ldots \ldots \ldots \ldots \ldots \ldots \ldots \ldots$ 
APPENDIX E: INTERNET PROCEDURES 


\title{
FIREDOC USERS MANUAL, 3rd EDITION
}

\author{
Nora H. Jason
}

\begin{abstract}
FIREDOC is the on-line bibliographic database which reflects the holdings (published reports, journal articles, conference proceedings, books, and audiovisual items) of the Fire Research Information Services (FRIS) at the Building and Fire Research Laboratory (BFRL), National Institute of Standards and Technology (NIST). This manual provides step-by-step procedures for entering and exiting the database via telecommunication lines, as well as a number of techniques for searching the database and processing the results of the searches.

This Third Edition is necessitated by the change to a UNIX platform. The new computer allows for faster response time if searching via a modem and, in addition, offers Internet accessibility. FIREDOC may be used with personal computers, using DOS or Windows, or with Macintosh computers and workstations. A new section on how to access Internet is included, and one on how to obtain the references of interest to you. Appendix F: Quick Guide to Getting Started will be useful to both modem and Internet users.
\end{abstract}

Key Words: databases; fire engineering; fire research; fire safety; information retrieval; information dissemination; manuals 


\section{INTRODUCTION}

FIREDOC is the on-line bibliographic database which reflects the holdings (published reports, journal articles, conference proceedings, books, and audiovisual items) of the Fire Research Information Services (FRIS) at the Building and Fire Research Laboratory (BFRL), National Institute of Standards and Technology (NIST). Each holding in FIREDOC consists of the usual bibliographic information including the title, author, journal, book, or conference identification, keywords, identifiers, and abstract (if available). The database may be searched for the occurrence of words, terms, or names in the bibliographic information. The number of occurrences is reported and the bibliographic information for these occurrences may be listed. The FIREDOC database currently contains information on approximately 80 percent of the 50,000 holdings in the FRIS collection. All new additions to the collection are being added to the database and there is an ongoing effort to incorporate existing holdings. This manual provides the instructions necessary to access FIREDOC. The FIREDOC Vocabulary List[1]* is a separate publication noting authorized keywords to be used in FIREDOC.

FIREDOC resides on a UNIX server using the bibliographic search program STAR. The system includes a number of directly connected personal computers at the Building and Fire Research Laboratory, two telephone lines modems capable of communication rates of up to 9600 baud, and ethernet access. Telephone line users will normally communicate with the FIREDOC system using a personal computer and a compatible communications package such as ProComm Plus**.

Many terminal emulations can be accommodated by the computer. Internet users should be able to use their regular TCP/IP and FTP software.

All communication costs are absorbed by the searcher. FIREDOC is normally available for bibliographic searching 23 hours a day Monday through Friday and 24 hours on the weekend. FIREDOC is not available from 8:30 to 9:30 AM EST or EDT Monday through Friday when maintenance is performed on the system. Assistance is available by contacting the author by telephone at (01)301/975-6862 during regular working hours (8:30 AM - 5 PM EST or EDT), or by FAX at (01)301/975-4052, or in writing.

*Number(s) within the brackets refer to the Bibliography at the end of the report.

**Within this paper certain commercial equipment, software, and/or trade names are included solely for the purpose of identifying those computer hardware and software products with which compatibility is required or has been verified. This identification does not imply recommendation or endorsement by the National Institute of Standards and Technology. 
This manual covers the techniques for using the STAR system to search the FIREDOC database. Appendices $D$ and $E$ are two examples on how to set up communications packages and to login and to logout of the system.

To obtain a FIREDOC identifier and password, and supporting documentation, contact the author by telephone: (01)301/975-6862; fax: (01)301/975-4052; email: birder@enh.nist.gov.

\section{SELECTING A COMMUNICATIONS PACKAGE}

Two communications packages have been identified as working with the STAR search program. They are to serve merely as examples of software, as many other communications packages are accepted. We have found that the VT100 and VT220 terminal drivers perform satisfactorily. No special software is needed for Macintosh computers. The key to using FIREDOC is to have compatible terminal drivers. It is no longer possible to use a TV950 terminal emulation. By using the examples found in Appendices $D$ and $E$, the user should be able to adapt other software. The communication packages are:

a. ProComm Plus Version 2.01 is a communications package which has been verified as being compatible with the STAR system. ProComm will operate on IBM PC, $\mathrm{XT}, \mathrm{AT}$ and compatible computers and supports Hayes and compatible modems. For complete ordering information, contact Datastorm Technologies, Inc., P. O. Box 1471, Columbia, MO 65205 Telephone: $314 / 443-3282$. The cost is approximately $\$ 130.00$.

b. PC/TCP Network Software for DOS, Version 2.05 is a communications package for use on Internet. It is available from FTP Software, Inc., 2 High Street, North Andover, MA 01845. Telephone: $508 / 685-4000$. The cost is approximately $\$ 400.00$.

\section{USING THE SEARCH PROGRAM}

When you are at the login screen, type in the identifier and password that have been assigned to you by the author in lower case characters.

After you have successfully logged into STAR with the communications package of your choice (see Appendices D or E for guidance), a WARNING announcement appears. After reading it, acknowledge by typing the word accepted as instructed on the screen. The word must be correctly typed; if not, the computer breaks the connection. If you have correctly typed the word, the STAR Main Menu (Figure 1) will appear.

Before proceeding to do a search, the terminal driver that matches your terminal type as defined in your communications software configuration must be correctly entered. For 
example, if you have your software configured for a VT100, select number 62 from the screen menu.

If your terminal driver is not listed, there are two options. If 65 is selected, a list of drivers accepted by the server are noted and your terminal type can be entered as instructed. However, if the terminal driver does not appear, press <Enter> (also referred to as <Return >) twice to return to the STAR Main Menu. At this juncture, select 52 and follow the instructions on how to select a format to identify the terminal driver. If the terminal driver is entered correctly, press $q$. If desired, the list of terminal drivers can be requested again by following the instructions. The terminal driver identification will be requested again, and if it is accepted after being input, then the computer responds "Your Terminal Driver is set to your selection". Press <Enter> again. For additional verification, select 51 to see the terminal driver name.

The search cannot commence unless the terminal driver is correctly selected and identified.

After each <Enter>, the STAR Main Menu reappears. At this point select 11 to begin the literature search. The STAR Search Screen (Figure 2) appears and the search strategy is entered.

Throughout this document several special keys on the personal computer keyboard will be referred to by their common abbreviations. For example, the symbol <Enter $>$ is used to indicate pressing the enter key. A list of selected special keys can be found in Appendix $\mathrm{C}$. The numbers preceding the commands are used to indicate the input sequence and should not be entered. 
SunOS Release 4.1.3 (CFRSTAR) \#2: Hed Mar 3 15:04:04 EST 1993 for assistance, call NORA H. JASON, 301/975-6862

\begin{tabular}{|c|c|c|}
\hline STAR & FILE MAINTENANCE & LOGOUT \\
\hline 11 SEARCH FIREDOC & $\begin{array}{l}21 \text { DIRECTORY DISPLAY } \\
22 \text { TYPE FILE } \\
23 \text { ERASE FILE (S) }\end{array}$ & 31 Locout \\
\hline FILE TRANSFER & SHOW TERMINAL DRIVER & SET TERMINAL DRIVER \\
\hline $\begin{array}{l}41 \text { STARCLEAH FILE } \\
\text { (same as old CLNCPY) }\end{array}$ & $\begin{array}{l}51 \text { SHOW TERMIHAL DRIVER } \\
52 \text { SEARCH FOR A } \\
\text { TERMINAL DRIVER }\end{array}$ & $\begin{array}{l}61 \text { SET TO TV955 } \\
62 \text { SET TO VT } 100 \\
63 \text { SET TO VT } 220 \\
64 \text { SET TO PCVISION } \\
65 \text { SET TO OTHER }\end{array}$ \\
\hline
\end{tabular}

Enter menu selection:

Figure 1. STAR Main Menu

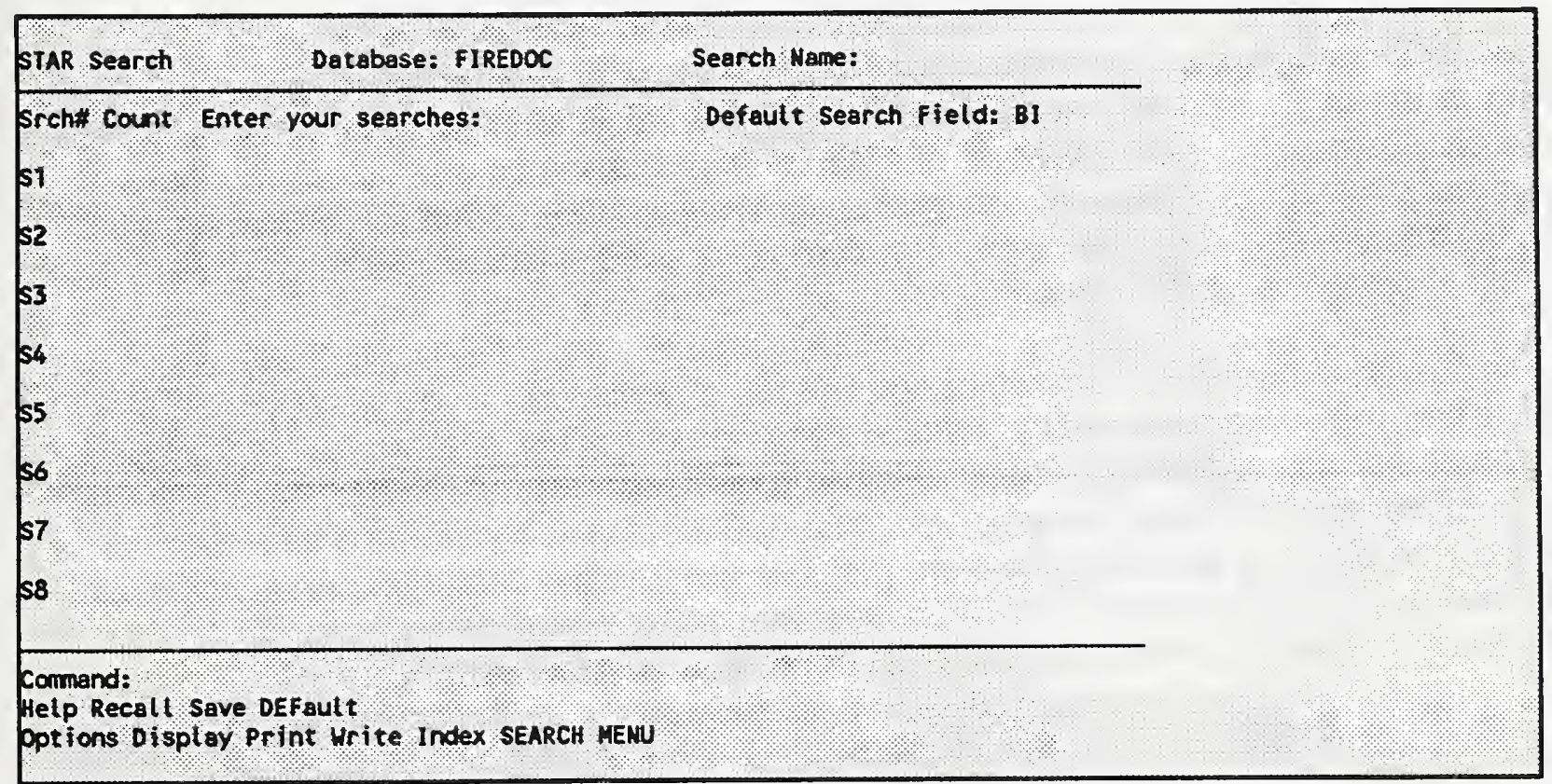

Figure 2. Partial Search Screen 
In Figure 2 search lines S1 through S8 may appear on the screen with solid or dotted lines; it depends upon how the communications package being used interprets the STAR screen write commands. The cursor begins at the line S1 and you are ready to commence a search. Before discussing the search procedures one should know how to exit STAR.

To exit STAR, from the Search screen press <Esc> to go to the Command line. On the Command line, type MENU <Enter>. Select 31 LOGOUT and then exit from your communications package.

To exit STAR from the Display screen, stop the scrolling by pressing the appropriate up or down arrow key; if the cursor is in the Command line type $E<E n t e r>$ to return to the Search screen. On the Command line, type MENU <Enter>. Select 31 LOGOUT and then exit from your communications package. In addition, one must know how to leave the program. See the Appendices $D$ or $E$ for guidance on a communications package or refer to your communications package manual. It is essential to know how to complete the logout procedure.

\subsection{Conducting a Search}

The main search screen contains a header at the top with the database name FIREDOC. On the left of the screen are S1 to S8 which are the search numbers. You will enter search expressions next to these numbers. The bottom of the screen contains the command line and two lines of acceptable commands. The use of these commands will be discussed later. You will notice that the cursor is now positioned next to S1 and is ready to accept a search expression.

Each search expression is limited to one line ( 66 characters). If you go beyond the end of the line, the cursor automatically stops at the end of the line and beeps. At the bottom of the screen the computer will say: Field is full. To correct the problem, erase the last incomplete word and any "dangling" Boolean operators (see Section 3.3 for a discussion of Boolean operators) so that the computer can execute the search expression. Search expressions which require more than one line can be accommodated using search numbers; this will be discussed later. To conduct a simple search type:

WOOD <Enter>

You will see the search in progress, and the number of "hits" or records in the database which contain the word will be displayed under the word. When the search is completed 
the total number of hits will appear in the Count column. An example of a portion of the search screen is shown below.

Any search which does not specify a specific field to search will search the basic index which includes words from the title, keyword, identifier, or abstract fields. Therefore, an author by the name of JANE WOOD would not be found. To include the author field, the format discussed in Section 3.5 must be used.

$\begin{array}{lcl}\text { Srch\# } & \text { Count } & \text { Enter your searches: } \\ \text { S1 } & 985 & \text { WOOD } \\ & 985\end{array}$

The numbers on your screen may be different from the examples in this document as the size of the database changes daily. As you might expect, there are a large number of records which contain the word WOOD and you would normally not want to display all of these. In the following sections we will discuss how to narrow your search. Note at the completion of your search expression the cursor has moved to search number S2. To conduct another search, type in another word, for example, WATER. A sample of a portion of the search screen is shown below.

$\begin{array}{lll}\text { Srch\# } & \begin{array}{l}\text { Count } \\ \text { S1 }\end{array} & \begin{array}{l}\text { Enter your searches: } \\ \text { WOOD } \\ \wedge 985\end{array} \\ \text { S2 } & 1145 & \begin{array}{l}\text { WATER } \\ \wedge 1145\end{array}\end{array}$

Although you have moved to your second search, the program retains the information about your first search. The program usually stores information on up to 24 searches at one time. You can see the other searches by using the arrow keys or the PgDn and PgUp keys. Note that only the search information moves and the top and bottom of the screen remains fixed.

If necessary, STAR can be expanded beyond 24 search lines. When you fill S24, to obtain additional search lines press <CTRL> $O$ for each line needed. If you do not need the previous 24 lines, you may erase all of the work and go back to $S 1$ by pressing $<$ EsC > and typing SEARCH in the Command line.

You may edit and rerun search expressions by using the arrow keys to move to a particular search and make corrections. Using the left and right arrow to move across search expressions does not change the characters. The keyboard is normally in the typeover mode, that is new characters will replace old ones. For example, move the cursor to $S 1$ and using the right arrow key to position the cursor over the $W$ in WOOD. 
Type a $F$ and the $W$ will be replaced by an $F$. Now press <Enter> and search $S 1$ will be rerun using the word FOOD.

There are several additional keys which are useful for correcting or modifying search expressions. The character over the cursor may be deleted using the space bar to blank out characters. In some software packages, the <Back Space> key may blank out characters. By pressing <CTRL> F one may insert one or more blank spaces. You can then insert the character(s) needed to complete your search.

\subsection{Searching Fields}

The information stored in the database for each record or document are contained in fields. The available fields and their abbreviations are given below.

$\begin{array}{ll}\text { AB } & \text { abstract } \\ \text { AU } & \text { author (all authors, including BSTAF and STAFF) } \\ \text { BC } & \text { book or conference proceedings name } \\ \text { BSTAF } & \text { NIST building research staff } \\ \text { CN } & \text { contract number } \\ \text { CS } & \text { corporate source, or where the author(s) work } \\ \text { ED } & \text { editor } \\ \text { DT } & \text { document type } \\ \text { ID } & \text { identifier(s) (words not listed in FIREDOC Vocabulary List) } \\ \text { JT } & \text { journal name } \\ \text { KW } & \text { keyword(s) (words listed in FIREDOC Vocabulary List) } \\ \text { LA } & \text { language (other than English) } \\ \text { ON } & \text { order number for report } \\ \text { PL } & \text { place of meeting } \\ \text { PUB } & \text { publisher } \\ \text { PY } & \text { year of publication of the work } \\ \text { RN } & \text { report or book number } \\ \text { SP } & \text { sponsor, or who paid to have the work done } \\ \text { STAFF } & \text { NIST fire research staff and grantees } \\ \text { TI } & \text { journal article title or report title }\end{array}$

Unless otherwise specified, only the basic index is searched. It uses words from the title, abstract, identifier and keyword fields. For better results, the search fields may be specified in either of two ways as illustrated by the following searches.

$\begin{array}{lcc}\text { Srch\# } & \text { Count } & \text { Enter your searches: } \\ \text { S3 } & 105 & \text { TI=SPRAYS } \\ & 105\end{array}$


Srch\# Count Enter your searches:

S4

105

SPRAYS/TI

$\wedge 105$

Both of these searches are the same and the search for the word SPRAYS is limited to the title field.

\subsection{Using Boolean Operators and Parentheses}

The system supports the Boolean or logical operators AND, OR, NOT and ADJ. A discussion of Boolean operators is contained in APPENDIX A. For example, try the following search expressions:

$\begin{array}{lll}\begin{array}{l}\text { Srch\# } \\ \text { S5 }\end{array} & \begin{array}{l}\text { Count } \\ 45\end{array} & \begin{array}{l}\text { Enter your searches: } \\ \text { WOOD AND WATER } \\ \text { ^985 }\end{array} \\ \text { S6 } & 2085 & \begin{array}{l}\text { WOOD OR WATER } \\ \wedge 985\end{array}\end{array}$

The S5 count shows the number of records in which both WOOD and WATER occur and the S6 count the number in which either WOOD or WATER occur. The numbers under WOOD and WATER show the number of records in which each word appears. When the Boolean operator OR is used, the sum may be less than the parts. If the terms appear in the same record, the count is one. Searches may be further defined by using Boolean operators and parentheses. Terms within the parentheses are processed first. For example, try the following search:

S7

\section{WATER AND (COMPARTMENTS OR ROOMS)}

^1145 ^411

In this case the $S 7$ count shows the number of records in which WATER can be found along with either COMPARTMENTS or ROOMS.

Boolean operators and parentheses also may be combined with fields as shown in the following examples. To increase the precision of the search, use the Adjacency feature. That is, use the ADJ operator to indicate that the two words should be next to each other in the order specified. Several examples follow. In S8 and S13 we are interested in information from the journal called Fire Technology; in S9 we are interested in information about carbon monoxide. 
The count for search $S 8$ shows the number of records in which the word FIRE immediately precedes the word TECHNOLOGY in the journal name field.

Following the <Enter> after search S8, the screen will scroll up for each succeeding search until S24 is reached.

The order of the search strategy is very important. If you only have one piece of precise information (in our example you know one word from the title field, TI) and you want to include a more global concept to be combined with the precise information, the best way to create your search strategy is:

Srch\# Count Enter your searches:

S9 $77 \quad$ (CARBON ADJ MONOXIDE) AND $\mathrm{TI}=\mathrm{TOXICITY}$

If you inadvertently forget this suggestion, and type the search strategy as:

S10

$$
\begin{aligned}
& T I=T O X I C I T Y \text { AND (CARBON ADJ MONOXIDE) } \\
& \text { ^ } 706 \\
& \text { ^ } 250 \\
& \wedge 159
\end{aligned}
$$

The count is very low because of a faulty search strategy.

The Count of 77 hits for S9 shows the number of records in which TOXICITY appears in the TITLE field and the words CARBON next to MONOXIDE appear together in either the title, abstract, identifier or keyword fields. This is the best format. In S10, the field (in the example TI) is first, the computer assumes all words are from the same field. Therefore, the Count is much lower than in the recommended search strategy format of S9. It is not uncommon to receive no match if the $\mathrm{S} 10$ format is used.

Another way to limit a search and to have it more meaningful, is to use the Boolean operator NOT . For example, if you wish to remove the word apartments from your search strategy for residential buildings, it would be input as:

S11 $\quad 482$

(RESIDENTIAL ADJ BUILDINGS) NOT APARTMENTS ^ 685 ^ 4649 ^ 153

Caution always should be exercised when using the NOT command as you may discard a valuable reference, such as a reference which discussed apartments along with houses or other types of residential buildings. Each user must weigh the options. 


\subsection{Using Search Numbers in the Search Expression}

Search numbers may be used in the search expression to accommodate long search expressions or as a means of narrowing a previous search. For example, try the following search using S6 and S8 from above.

Srch\#

Count

28

Enter your searches:

S12

$\wedge 2085 \wedge 450$

This would be equivalent to:

513

28

(WOOD OR WATER) AND JT=(FIRE ADJ TECHNOLOGY

$$
\wedge 985 \wedge 1145 \wedge 7557 \wedge 1089
$$

You may use any combination of previously used search numbers along with search statements. For example, try the following search.

S14

17

S8 AND KW= TOXICITY
$\wedge 450$
$\wedge 1274$

3.5 Using Wildcard Characters in the Search Expression

The character * (known as the asterisk or star) may be used as a wildcard character (sometimes called a truncation or global character) at the end of a search word. NEVER USE THE WILDCARD CHARACTER AT THE BEGINNING OF A WORD because it will serve as a prefix and cause the computer to look at all possible combinations. The use of this character indicates that a hit will occur when any character or string of characters is present in its place. The wildcard character is most commonly used to search for a word in both singular and plural forms, British spellings, and to search for authors whose names may be incomplete.

Srch\# Count . Enter your searches:

S15 $502 \quad$ SPRAY*

^502

Search S15 will find the records with any word or combination of words beginning with SPRAY in the title, abstract, identifier or keyword fields. 


\subsubsection{Using Wildcard Characters in the Author Search}

It should be noted that the entire author's name, including initials, is considered as a single word. Therefore, searching the author field for a last name without initials and without the wildcard character will generally result in no hits. The best results for searching an author's name is to use the last name, followed by a comma, a space, and the first initial followed by the wildcard symbol, as the second initial is not always used. For example, try the following searches.

Srch\# Count Enter your searches:

S16

138

$$
\begin{array}{r}
A U=\frac{L E V I N *}{\wedge} 138
\end{array}
$$

S17

94

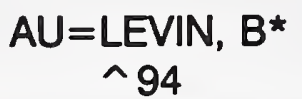

Search S16 will find the records with authors whose names begin with LEVIN (for example LEVINSON) and S17 the records with authors with the last name of LEVIN and the first initial of B. The space after the comma is significant because the author's name is always entered with the space. Try the following search.

S17

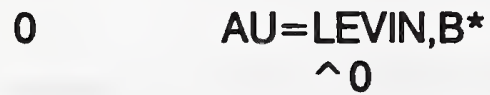

The Count was 0 because a space is REQUIRED between the surname followed by a comma and the first character. Additional information on searching the author field is presented in Section 3.7.

\subsection{Using the Command Line}

The command line at the bottom of the screen is used to enter commands to the STAR program. To move the cursor to the command line, press <Esc>. The statement Enter a Command will appear. The cursor can be moved back to the search line with an $<E s c>$. Thus the <Esc $>$ acts as a toggle between the search and command lines. An $<$ Enter $>$ is not required after the <Esc > key.

Below the command line are two lines of acceptable commands. The commands in the first menu line are in upper and lower case and only the upper case letters should be typed to initiate these commands (e.g., $\mathrm{H}$ for Help, $\mathrm{S}$ for Save). The commands in the second menu line are: Options, Display, Print, Write, Index, MENU. (REMEMBER, this 
second line may not be visible with your communications package.) When you move to other screens in the STAR program, different menus will appear.

To enter a command, type the uppercase letter(s) of the command name followed by an $<$ Enter>.

The MENU command returns you to the STAR Main Menu. **WARNING!** When you return to the STAR Main Menu all of the search expressions you have entered will be cleared. You may want to wait and try this command later in your session.

The Help command (type $\mathrm{H}$ <Enter> and then $1<$ Enter>) provides instructions and guidelines on how to use the STAR program. Type $E$ to return to the main search screen. The Help command on some of the screens discussed below has not been implemented and results in no action. If assistance is needed, use the FIREDOC Users Manual or contact the author.

The Print command should $\star \star N E V E R^{\star \star}$ be used. This will cause the program to go into an endless wait to send a command to a nonexistent printer. To cancel the command, press CTRL C . See Section 3.11 for a discussion of how to obtain a printed copy.

The rest of the commands will be discussed in the following sections.

\subsection{Using the Index Feature}

The index (or directory) contains an alphabetized list of all of the searchable words in the database along with the field in which the words appear. As you might expect, this is a rather large list. The index command allows one to examine selected parts of this list for searchable words.

Use of the index command may be made when a search fails to turn up the expected number of hits. By using the index feature you may examine the searchable words in the database and revise the search strategy. To initiate the index feature, press <Esc> to move to the command line and type:

INDEX <Enter>

The STAR Index screen is drawn and you are looking at the beginning of the index. The Home and End keys move the display to the top or bottom of the index. The PgUp and PgDn keys move the index display one screen up or down. Note: PgUp and PgDn cannot be used with ProComm. The up and down arrows start the index display scrolling up or down. To start or to stop the scroll, lightly press an arrow key in the desired direction. You may notice that the index contains numbers and symbols as well 
as words. There are two commands, Near (N) and Field (F), which allow one to look at a part of the index of interest. The Near $(N)$ command shifts the index display to the area of a given word. For example, try:

N FIRE <Enter>

The index display moves to those words near FIRE. The left side of the display shows the field in which the word is found. The Field ( F ) command limits the display to selected fields. For example, try:

N LEVIN <Enter >

F AU <Enter>

The first command displays words near the word LEVIN and the second command limits the display to the author field only. We now only see the authors whose names are near LEVIN. The Fields command with no fields indicated returns all fields. If a display is taking too long to create, you may abort the procedure by pressing <Esc> .

To return to the search screen, type:

SEARCH <Enter>

If you type MENU, you will lose your previous search expressions and be returned to the STAR Main Menu.

\subsection{Saving and Recalling Searches}

The search expressions created in a session may be saved in a file on the server for use at a later time. Note that the program saves only the search expressions and not the search results. To save a search session, move to the command line and type $S$ followed by a title (maximum of six alphanumeric characters) you wish to give the search and an <Enter>. You may later recall the search by this title so be sure to make a note of it. If you type $S$ and no name, the program will ask for a search name and place it in the upper right corner of the screen. Because of the limited space available in the computer, all saved searches will be deleted by 9:00 AM each Friday. After saving the current search expressions you may clear the current search by returning to the STAR Main Menu and then select 11 SEARCH FIREDOC <Enter> to begin a new session with S1. An example save command is:

S SMITH1 <Enter> 
To recall a previously saved search session type $R$ followed by the name with which it was saved. An example recall command is:

R SMITH1 <Enter>

This will clear any existing search expressions and retrieve the saved expressions.

The search will scroll through on the screen and then return to the top of the search screen.

\subsection{Displaying the Search Results}

The Display command is used to list on the screen the references or hits from a search expression. For example, move to the command line by pressing the <Esc> key and type the following Display command to view the results of search S11 above.

\section{S11 BIB1 <Enter>}

The $D$ in the command is for Display, the S11 the search number, and BIB1 is the format of the display. The screen will be redrawn and the information for each of the hits in the search will be written on the screen. To continue Display in ProComm, press the down arrow key. (If the <Enter> key is pressed, the scrolling will stop and the last reference will appear.) To start and stop the display, use the appropriate arrow keys. To abort the display, in the Command line type $\mathrm{E}$ <Enter> while the display is paused. The use of some communications packages will result in the display pausing at the end of each screen. To continue, press the down arrow key. From time to time you may see a line full of the symbol $\wedge \wedge \wedge$ in the display. This indicates the end of a page. When the display is complete, the cursor moves to the command line. To return to the search screen, type $E$ for End.

There are four formats and the information which would be displayed for each is given below. The information provided in each bibliographic record depends upon the information available.

Format 1: $\quad$ BIB1 $=$ Title of work and book/conference proceeding name if appropriate. [TI/BC]

FIREDOC Users Manual. Revised. 
Format 2: $\quad B I B=A u t h o r(s)$; report title or title of journal article; corporate source(s); report number; pagination; publication date; distribution (i.e., where to obtain the report); order number. [AU; TI; CS; RN; CITER;PY; DI; ON]

Jason, N. H.

FIREDOC Users Manual. Revised.

National Bureau of Standards, Gaithersburg, MD

NBSIR 87-3562; 39 pp. September 1987.

Available from National Technical Information Service

PB90-271800

Format 3: $\quad$ BIB2 $=\quad$ Author(s); title of work; corporate source(s); report number; pagination; distribution; order number; keyword(s); abstract. $A U ; T I ; C S ; C I T E R ; D I ; O N ; K W ; A B]$

Jason, N. H.

FIREDOC Users Manual. Revised.

National Bureau of Standards, Gaithersburg, MD

NBSIR 87-3562; 39 pp. September 1987.

Available from National Technical Information Service

PB90-271800

information retrieval; fire research; information dissemination;

databases; manuals; information transfer

FIREDOC is the on-line bibliographic database which reflects the holdings (published reports, articles, books, and audiovisual items) of the Fire Research Information Services (FRIS), at the Center for Fire Research, National Bureau of Standards. This manual provides a step-by-step technique for entering and exiting the database via telecommunication lines, as well as a number of techniques for searching the database and processing the results of the searches.

Format 4: $\quad$ PUBL $=$ Author(s); title of work; corporate source(s); report number; distribution; order number. [AU; TI; CS; CITER; DI; ON]

Jason, N. H.

Jason, N. H.

FIREDOC Users Manual. Revised.

National Bureau of Standards, Gaithersburg, MD

NBSIR 87-3562; 39 pp. September 1987.

Available from National Technical Information Service

PB90-271800 
With some practice you may be able to modify the Display command using the following rules. If you omit the format then the most recent format you have selected will be used. If it is the first display, then BIB1 is used.

If you type $D$ all hits of the most recent search will be displayed and the most recent format selected will be used.

\subsection{Using the Options Command}

The Options command is used to examine the display and to write and/or to modify the formats if desired. To view the options screen, move to the Command line and type $O$ <Enter>. An example of the options screen is shown below.

Search (Record Set): $\quad$ S13

Report Format Name: BIB1

Output Fields: $\quad$ TI BC

Sort by:

Page Format: $\quad$ SORTBIB1

Report Title: $\quad$ SMITH1 on 07/21/93 18:00:45

Printer Name: $\quad$ HP

Disk File Name: $\quad$ SMTH1.LST

Using the cursor movement keys, the display options may be displayed as desired. The "Search (Records Set)" is the number of the search expression. The Report Format Name may be either BIB1, BIB, BIB2 or PUBL. If Report Format is to be changed, type in the new format and the output fields will change to reflect the new format. The "Sort by" may remain blank (see Section 5.2 Advanced Display/Print Techniques if you are an experienced user) and the "Page Format" name should remain SORTBIB1. The printer name refers to a printer connected directly to the server and cannot be altered. The "Disk File Name" will be discussed in the next section.

To return to the search screen, move to the Command line and type:

E <Enter>. 
The Write command is used to obtain a printed or disk copy of the search results. The STAR program contains no direct provision to log the display directly to your PC's printer or disk. To obtain a printed copy of the search results, you must write the search results to a file on the server, remove the control characters from that file, transfer that file to your PC, and print out that file. The following steps must be followed to obtain a printed copy of the search results.

After you have completed a search expression and you want printed results, press <Esc> to move the cursor to the command line and enter the Options command. Type

1. $0<$ Enter $>$

As discussed in the options command section, ensure that the proper search and format have been selected.

\section{Check format options}

Move the cursor to the "Disk File Name" field. You will see a file name which begins with your User ID followed by .LST. The search results should be sent to a unique file name. Normally a searcher will use his/her surname or some variation. For example, if your user ID is RUBB when you first look at the options screen, the file name RUBB.LST will appear. If your surname is SMITH you might use SMTH1.LST. The file name, that is, that part before the .LST, must be no more than five alphanumeric characters (letters and numbers). Do not use your Identifier as it may be confused with someone else's Identifier.

If several sets of search results are sent to the same file the results will be stacked in the file. Normally these files will be deleted each Friday so you may reuse your file name each week. If you need to write to a file several times in a week then you should vary the file name. Be sure you note the file names you have used as you will need to know them later. When you have completed the options you wish to change, press $<$ Esc $>$ to return to the Command line.

\section{Write output}

To write the search results to a file, press $<E s c>$ to go to the Command line, then type $W<$ Enter $>$. The program will display the status of the writing and the cursor will return to the Command line when it is complete.

Writing the results of a search is different than saving the search expressions with a Save command. The Write command writes the information which you see using the Display 
command to a file, while the Save command retains the search expressions in a file for retrieval with the Recall command.

When the writing is complete, type $E<E n t e r>$ to return to the Search Screen. If you wish to conduct any additional searches, to save search expressions, or to display or to write the search results, these activities should be completed before moving to the next step because it will clear all search expressions.

4. E $<$ Enter $>$

Move to the command line and type MENU <Enter> to return to the STAR Main Menu.

5. MENU <Enter>

The response is STAR Session Ended.

You are back at the STAR Main Men!!

The control characters MUST BE REMOVED from the file you wrote before transferring that file to your PC or workstation. If this step is omitted the file transfer will be unreadable. To remove the control characters use the routine STARCLEAN. From the File Transfer section of the menu select:

\section{41 STARCLEAN FILE <Enter>}

In your case the oldfilename is the file name you wrote to, which in the example above was SMTH1.LST. The new filename should be the same as the oldfilename with TXT substituted for LST. In our example the command becomes:

Please enter the file to clean: $\quad$ SMTH1.LST

Please enter name for cleaned file: $\quad$ SMTH1.TXT <Enter>

The response is:

Copying SMTH1.LST to SMTH1.TXT...

Copy Complete. STAR heading line removed.

$x$ control characters removed.

Where " $x$ " is the actual number of control characters removed. At the bottom of the screen the response is:

Press RETURN to continue: <Enter> 
For additional instructions on how to transfer the file, go to the Appendix in this manual which represents your communications software or your own manual.

\section{TROUBLESHOOTING}

The following is a list of commonly identified problems and their solutions. If your problem is not among them, please contact the author.

1. If a message is received that the STAR system is not active, and it is within the operating hours schedule, the system may need to be activated. Telephone 301/9756859 and inform the FRIS staff of the problem.

2. If upper case characters are used to login, the server will respond in a strange fashion. Press 31 LOGOUT <Enter> and then re-enter the Identifier and Password correctly in lower case characters.

3. If the correct terminal driver or correct communication parameters are not selected, meaningless characters will appear on the screen. Return to the communications package to be sure that the setup is correct.

4. If you have a workstation and are using an $X$ window system (Columns $=80$, Lines $=65$ ), the terminal driver is identified as: $x$ term . If you are using a small $X$ window system (Columns $=80$, Lines $=24$ ), then the terminal driver is identified as: xterms .

5. If you have a Sun Microsystems workstation console (Columns $=80$, Lines $=34$ ), the terminal driver is identified as: sun . If you have a Sun 48 line window (Columns = 80 , Lines $=48$ ), the terminal driver is identified as sun-48.

6. If the typed characters on the screen are not legible, it may be necessary to adjust the color pallet. As not all terminal drivers have adjustable color pallets, it may be necessary to change the terminal driver. Consult your software manual.

7. If the cursor is in the middle of a blank screen or a search strategy, press <Esc> and in the Command line type MENU to return to the Star Main Menu and select 11 SEARCH FIREDOC. 
8. If 11 SEARCH FIREDOC is selected from the Star Main Menu and an almost blank screen appears, press <Esc> and in the Command line type MENU. At the Star Main Menu select 51 SHOW TERMINAL DRIVER ; it should be the same terminal driver as selected in your software. Check this information before proceeding. Next, select the correct driver using either 65 SET TO OTHER or 52 SEARCH FOR A TERMINAL DRIVER. Lastly, reselect 11 SEARCH FIREDOC .

9. If, during a session, the screen begins to flash and the display cannot be read, the display and the communications program is out of synchronization with STAR. Although this rarely happens, it is possible to synchronize the two programs by returning to the STAR Main Menu, then to 11 SEARCH FIREDOC, and back to the STAR Main Menu. However, all searches will be lost.

10. If the screen freezes before getting into FIREDOC and 31 (for 31 LOGOUT) cannot be typed, then press <CTRL> ] q to abort the session.

11. If an improper search is initiated, for example *WOOD, the system will attempt to search the entire database for a "match". To stop the search, press $<$ CTRL $>1$.

12. If using ProComm Plus and the Display does not advance, press the down arrow key twice.

13. If at the STAR Main Menu and ? is pressed or Help typed, and an almost blank screen, press <Esc> to return to the STAR Main Menu.

14. If the <Esc $>$ key does not work, use $<$ CTRL $>[$ '

15. A direct dump cannot be made of a search session. If references are to be downloaded, then first use the STARCLEAN FILE function (see Section 3.11). 


\section{USING ADVANCED TECHNIQUES}

There are many ways to save time when you are searching FIREDOC and also some interesting ways to present your results. Listed below are some examples of what can be done.

\subsection{Advanced Searching Techniques}

1. Search for multiple authors:

Srch\# Count Enter your searches:

S1 $104 \quad A U=\left(E V A N S, D^{*}\right.$ OR BUDNICK, *)

$$
\text { ^ } 83
$$

2. To search for an editor:

S2

$85 \quad E D=J A S O N, N^{*}$ ^ 85

3. To narrow Search Statement $S 1$ to more than one publication year, range the numbers:

S3

22 S1 AND PY $=1990: 1991$

^ $104 \backsim 4736$

In this example the references from S1 are searched for only the years 1990 or 1991.

4. Search for title words next to each other and written by an author for which you do not have the complete name:

S4

$9 \quad \mathrm{TI}=\left(\right.$ CARBON ADJ MONOXIDE) AND AU $=\mathrm{LE}^{*}$

^250 159

^ 760

5. Search for a report number:

S5 $\quad 1 \quad$ RN=NISTIR 4441

$\wedge 1$

S5 also may be written as:

S5

$1 \quad$ RN="NISTIR 4441"

^1

The quotation marks tell the computer that the format may not be exactly as written, and it can recall the correct report number. 
6. Search for a report number with partial information:

Srch\# Count Enter your searches:

S6

$$
5 \quad \mathrm{RN}=\underset{\wedge 5}{\mathrm{NIST}-\mathrm{GCR}-88^{*}}
$$

Another option is to use the INDEX feature (see Section 3.7).

7. Search for papers by authors from Japan presented at a conference called UJNR.

S7

$$
203
$$

$$
\begin{aligned}
& \mathrm{CS}=(\text { JAPAN OR JAPANESE }) \text { AND } B C=U J N R \\
& \text { ^1046^16 } \\
& \text { ^ } 411
\end{aligned}
$$

S7 also may be written as:

S7

203

$$
\begin{aligned}
& C S=J A P A N * A N D B C=U J N R \\
& \wedge 1051 \text { ^411 }
\end{aligned}
$$

Caution always is advised when truncating a word, as you want to obtain meaningful information. There were more Corporate Source references, but the conference called "UJNR" limited the results and the net result is the same in either search. This is not always the case.

8. Search for an official keyword from the FIREDOC Vocabulary List.

S8

$$
496 \mathrm{KW}=\begin{gathered}
\text { SPRINKLER SYSTEMS } \\
\wedge 96
\end{gathered}
$$

Caution is advised when narrowing a search by keyword(s) as not all documents are indexed in-depth.

9. Other ways of searching for keyword(s):

S9

$$
223
$$

$$
\begin{gathered}
K W=\text { "BURNS (INJURIES)" } \\
\text { ^223 }
\end{gathered}
$$

In this example the quotation marks are essential, even though they are not noted in the FIREDOC Vocabulary List. If they are not used the computer will reject the format and look for a Boolean operator before the parenthesis. 
Search\# Count Enter your searches:

S10 $22 \quad \mathrm{KW}=\mathrm{FT}-\mathrm{IR}$ ^22

Quotation marks are not necessary in this example as the computer interprets this as one keyword.

10. Combine a number of search statements. The computer will insert the Boolean operator OR between the search statements. However, be sure that you do not include any unwanted search statements. In this example search statements 1 through 4 are combined by using the Boolean operator OR .

S11 $\quad 107 \quad$ S1:S4

$\wedge 107$

11. Search for publications by the NIST fire research staff and their grantees published during 1993.

$\mathrm{S} 12$ 5 STAFF $=$ YES AND PY $=1993$

^2814 52

12. Limit a search for a specific time period. This example is useful for quick updates over a specific time period. In this example the time period covered is from August 1 , 1993 through September 21, 1993.

$\mathrm{S} 13$

442

STAMP $=19930801: 19930921$

$\wedge 442$

\subsection{Advanced Display/Print Techniques}

Now we will look at different ways of presenting search results. All of the work is done in the Report Options screen. To go there after you have completed searching, press <Esc> and in the Command line press 0 .

You should only adjust the following fields on the screen:

Search (Record Set); Report Format Name; Output Fields; Sort by. 
The following examples are to illustrate how to use the various features. They are:

1. Arranged alphabetically by the first author. You want the references to contain only the author(s), title(s), corporate source and report number(s). After making the necessary additions and deletions, the STAR Report Generation Screen will then look like:

Search (Record Set): $\quad$ S12

Report Format Name: PUBL

Output Fields:

Sort by:

AUSB/S[5,60] AUX[15,60] TI[15,60] CS[15,60] RN $[15,60]$

AUX

The PUBL format is discussed in Section 3.9. AUSB/S is the command to the computer to highlight in bold the first author's name (this feature may not be possible with all computers). The numbers within the brackets are the spacing on the page. AUX is the combined author field and the Sort only will be by the first author of the reference; $\mathrm{TI}$ is the report or journal article title (if you are doing a book or conference proceedings title, the field is $\mathrm{BC}$ ); $\mathrm{CS}$ is the corporate source or the name of the author's company; RN is the report number.

2. Sorted by the most recent references first. The BIB format is used.

Search (Record Set): $\quad$ S12

Report Format Name: BIB

Output Fields:

Sort by:

AUX[5,60] TI CS SP CITE CITER CITEC CITEC1 DI ON PY/D

The BIB format is discussed in Section 3.9. AUX is the combined author field and listed as it appears on the page of the reference. $\mathrm{TI}$ is the journal or report title. CS is the corporate source or the name of the author's company. SP is the sponsor of the research activity. CITE (etc.) establish the bibliographic format for each type of work. $\mathrm{DI}$ is the distribution source. ON is the order number. PY is publication year and $/ \mathrm{D}$ is the command to organize the references in descending order.

3. Sort by the title and have the title appear first. In addition, we want the Keywords to be printed and indented to make them easier to identify. In some instances where the reference may be a proceedings, it may be necessary to add $B C$ to the Output Field and to the Sort by: field. The PUBL format is used. 
Search (Record Set): $\quad$ S12

Report Format Name: PUBL

Output Fields:

TI[5,60] AUX[15,60] CS[16,50] CITE[15,60]

CITER[15,60] CITEC[15,60] CITEC1[15,60] DI[15,60] ON[15,60] KW[18,60]

Sort by:

$\mathrm{TI}$

Caution. The screen will say: Press CTRL-C to Interrupt. Only do this if you wish to abort the search. This command will disconnect you and all of your work will be lost.

If you continue to search, make the Sort by: blank. To return to the STAR Screen, press <Esc> and type $E$ <Enter>. When you are ready to Display again, it is recommended to initiate a new command.

\section{OBTAINING THE REFERENCES}

Each reference has as complete a uibliographic citation as possible. Obtaining copies of the references depends upon your resources: personal, corporate, and/or public or university library.

To order documents in the NISTIR or NIST-GCR series, use NTIS. The address is: National Technical Information Service, 5285 Port Royal Road, Springfield, VA 22161. Telephone: $800 / 553-6847$ or (01)703/487-4650. When possible, each reference has the NTIS Order number. They accept major credit cards or a deposit account may be established for continuous charging.

To order documents from GPO in the NIST Technical Note, NIST Handbook, or NIST Special Publications series, the address is: Government Printing Office, U. S.

Superintendent of Documents, Washington, DC 20402. They also may be contacted by telephone; the Order Desk telephone number is (01)202/783-3238.

For other U.S. government publications, contact either NTIS or GPO. For all other references local resources should be used.

\section{ACKNOWLEDGEMENTS}

Special appreciation and recognition is due Messrs. Emil Braun, Richard D. Peacock, W. Douglas Walton and James W. Raines. Their contributions to the testing of FIREDOC and the resultant Manual have been very important. Special mention must be made of Kathleen B. Whisner's contribution. She has keyed in almost all of the records. Without her effort, there would be no FIREDOC to search. The efforts of other BFRL and NIST 
staff also are gratefully acknowledged, in addition to the users in the international fire community who participated in the alpha and beta tests.

\section{BIBLIOGRAPHY}

1. Jason, Nora H. FIREDOC Vocabulary List, 3rd Edition, NIST Special Publication 779, National Institute of Standards and Technology, Gaithersburg, MD, February 1990, 104 pp. 


\section{Appendix A: BOOLEAN OPERATORS}

You may use the three Boolean operators: AND, OR, NOT. Their function is depicted in the Venn diagrams noted below.

Search Expression

A AND B

A OR B

A NOT B

A ADJ B Not Applicable
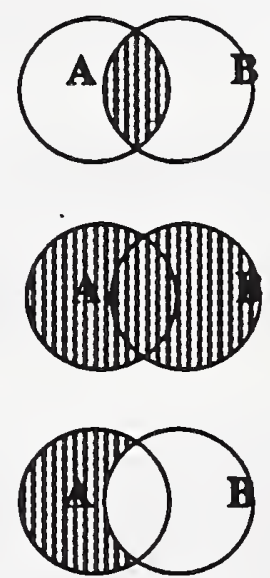

Venn Diagram
The shaded part represents those records that contain TERM A but not TERM B.

The shaded part represents those records that contain BOTH terms.

The shaded part represents those records that contain EITHER term, including records that contain both terms.

Those records that have nothing else between Term $A$ and Term B.

There are some general rules to keep in mind. The computer always processes:

terms within parentheses first, and

A before $B$. 


\section{APPENDIX B: ABBREVIATIONS, COMMANDS, DISPLAY/PRINT FORMATS}

Search field abbreviations:

$\begin{array}{ll}\text { AB } & \text { abstract } \\ \text { AU } & \text { author (all authors, including BSTAF and STAFF) } \\ \text { BC } & \text { book name or conference proceeding name, location, date(s) } \\ \text { BSTAF } & \text { NIST building research staff } \\ \text { CN } & \text { contract number } \\ \text { CS } & \text { corporate source, or where the author(s) works } \\ \text { DT } & \text { document type (journal; report; book; proceedings; video) } \\ \text { ED } & \text { editor } \\ \text { ID } & \text { identifier (uncontrolled vocabulary) } \\ \text { JT } & \text { journal name } \\ \text { KW } & \text { keyword(s) [words listed in the FIREDOC Vocabulary List] } \\ \text { LA } & \text { language (other than English) } \\ \text { ON } & \text { order number } \\ \text { PL } & \text { place of conference } \\ \text { PUB } & \text { publisher } \\ \text { PY } & \text { year of publication of work } \\ \text { RN } & \text { report or book number } \\ \text { SP } & \text { sponsor, or who paid to have the work done } \\ \text { STAFF } & \text { NIST fire research staff and grantees } \\ \text { TI } & \text { title of report or journal article }\end{array}$

Commands:

To move to the Command line, press <Esc>

To clear all search expressions, press <Esc> and type in the Command line SEARCH <Enter>.
A Display command is: D S1 BIB <Enter>

To pause and restart the display, use up or down arrow keys

To abort the display, press <Esc>, and then type $E<E n t e r>$. 
Display/Print formats. [These are unique groupings, solely for this purpose.]

BIB1 = Title of work and book/conference proceeding title if appropriate. [It appears as: TI BC]

BIB $=$ Author(s); title of work, journal title, report number(s), page(s), publication date.

[It appears as: AUX[5,60] TI CITE CITER CITEC CITEC1 DI ON]

BIB2 = Author(s); title of work; date; corporate source(s); sponsor(s); date of publication; journal title; report number(s); Library of Congress book number; who can access the document; order number; language, if not English; contract number; keyword(s); identifier(s); abstract.

[It appears as: AUX[5,60] TI CITE CITER CITEC CITEC1 DI ON LA CN KW ID AB

PUBL = Same content as BIB but formatted differently; the first author is at the far left margin and may be highlighted. The numbers within the brackets are column locations and can be adjusted.

[It appears as: AUSB/S [5,60] AUX[15,60] TI[15,60] CS[15.60] CITE $[15,60]$ CITER $[15,60]$ CITEC $[15,60]$ CITEC $1[15,60]$ DI $[15,60]$ ON[15,60] LA[15,60] CN $[15,60]$ 
APPENDIX C: DESIGNATION AND USE OF KEYS ON PC KEYBOARD

\section{FUNCTIONS KEYS}

$\begin{array}{lll}\text { Key } & \text { Name } & \underline{\text { Action(s) }} \\ \text { Enter } & \begin{array}{l}\text { enter or } \\ \text { carriage } \\ \text { return }\end{array} & \begin{array}{l}\text { enters command; } \\ \text { moves to return } \\ \text { to following line }\end{array} \\ \text { ESC } & \text { escape } & \begin{array}{l}\text { moves cursor to } \\ \text { Command or Search line; } \\ \text { aborts search procedure }\end{array}\end{array}$
Alt alternate
Ctrl control
End end
moves display to bottom
of list (display)

\section{EDITING KEYS}

$\begin{array}{lll}\text { Key } & \text { Name } & \underline{\text { Action(s) }} \\ \begin{array}{l}\text { Backspace } \\ \leftarrow\end{array} & \text { backspace } & \begin{array}{l}\text { deletes character to left } \\ \text { of cursor }\end{array} \\ \text { PgUp } & \text { page up } & \begin{array}{l}\text { ProComm: Download protocols; } \\ \text { others: moves displays up one } \\ \text { page }\end{array} \\ \text { PgDn } & \text { page down } & \begin{array}{l}\text { ProComm: Upload protocols; } \\ \text { others: moves display one page }\end{array} \\ \downarrow & \begin{array}{l}\text { down arrow } \\ \text { up arrow } \\ \text { left arrow } \\ \text { right arrow }\end{array} & \begin{array}{l}\text { moves cursor in direction } \\ \text { noted }\end{array} \\ \rightarrow & \end{array}$




\section{APPENDIX D: PROCOMM PLUS PROCEDURES}

ProComm Plus is produced by Datastorm Technologies, Inc. The address is: Datastorm Technologies, Inc., P. O. Box 1471, Columbia, MO 65205. The 24-hour, 7 days per week hotline is: $314 / 875-0530$.

Install ProComm Plus on your computer using the information provided in the ProComm documentation. To set the parameters in ProComm start the program by typing:

1. PCPLUS <Enter>

ProComm Plus responds with an initial screen. Press any key to continue. The next several steps will set up ProComm to interact with the server using STAR. Press

2. $\quad$ Alt $S \quad<$ Enter $>$

3. Select Modem Options

To initiate the modem command options for 1200,2400 or 9600 baud, they should appear as:
A. Initialization command .... ATE1 S7 $=60 \mathrm{~S} 11=60 \mathrm{~V} 1 \mathrm{X} 1 \mathrm{Q0} \mathrm{S0}=0^{\wedge} \mathrm{M}$
B. Dialing command ...... ATDT (for touch tone) or ATDP (for dial telephone)
C. Dialing command suffix ...^ $M$
D. Hangup string ........ $\sim \sim \sim++\sim \sim \sim$ ATHO^M
E. Auto answer on command.. $\sim \sim \sim+++\sim \sim \sim$ ATHO^M
F. Auto answer off command .. $\sim \sim \sim+++\sim \sim \sim$ ATSO $=0 \wedge M$

Use <Esc> to exit then select:

4. Terminal Options <Enter>

For the terminal setup. It should appear as:
A. Terminal emulation
VT100
B. Duplex
FULL
C. Soft flow control
ON
D. Hard flow control
OFF 


$\begin{array}{lll}\text { E. } & \text { Line wrap } & \text { ON } \\ \text { F. } & \text { Screen scroll } & \text { ON } \\ \text { G. } & \text { CR translation } & \text { CR } \\ \text { H. } & \text { BS translation } & \text { DESTRUCTIVE } \\ \text { I. } & \text { Break length (millisecs) } & 350 \\ \text { J. } & \text { Enquiry (EMQ) } & \text { OFF } \\ \text { K. } & \text { EGANGA true underline } & \text { OFF } \\ \text { L. } & \text { Terminal width } & 80 \\ \text { M. } & \text { ANSI } 7 \text { or } 8 \text { bit commands } & 8 \text { BIT }\end{array}$

Use <Esc> to exit. You may save the setup to disk for future use by pressing S. Use $<$ Esc $>$ to exit the setup menu. Press:

5. Alt $\mathbf{P}$

For Line Settings.

Select:

\section{$1200, N, 8,1$ OR $2400, N, 8,1$ OR $9600, N, 8,1$}

COM port where your modem is connected

Press Alt $S$ to Save and Exit.

You are now ready to start the dialing sequence. Press:

6.

Alt D

To include the FIREDOC information in the dialing directory, press:

8.

R <Enter >

The FIREDOC telephone number is $301 / 948-4997$ or $301 / 948-4998$. The other parameters are:

\begin{tabular}{|c|c|c|c|c|c|c|c|}
\hline baud & 1200 & OR & baud & 2400 & OR & baud & 9600 \\
\hline $\mathbf{P}$ & $\mathbf{N}$ & & & $\mathbf{N}$ & & & $N$ \\
\hline D & 8 & & D & 8 & & D & 8 \\
\hline$S$ & 1 & & $S$ & 1 & & $S$ & 1 \\
\hline$D$ & $F$ & & D & F & & $\mathrm{D}$ & $F$ \\
\hline$P$ & D & & $\mathbf{P}$ & $D$ & & $P$ & $D$ \\
\hline
\end{tabular}


The modem dial command may require changing to accommodate tone or pulse dialing. For other than Hayes compatible modems see your modem manual for information. Press the correct directory number and then press <Enter>. The computer responds (all computer responses are underlined):

\section{$\underline{\text { CONNECT } 1200 \text { OR CONNECT } 2400 \text { OR CONNECT } 9600}$}

\section{FIREDOC Login:}

You are at the Login screen where you type [in lower case character(s)] in your User ID and the Login Password (this will not appear on the screen). After you have successfully logged into STAR with the communications package of your choice (see Appendices D or $\mathrm{E}$ for guidance), a WARNING announcement appears. After reading it, type the word accepted. The word must be correctly typed to advance, otherwise the computer breaks the connection. If you have correctly typed the word, the STAR Main Menu (Figure 1) will appear.

Before proceeding to do a search, the terminal driver that matches your terminal type as defined in your communications software configuration must be correctly entered. For example, if you have your software configured for a VT100, select number 62 .

If your terminal driver is not listed, there are two options. If 65 is selected, a list of drivers accepted by the server are noted and your terminal type is entered as per the instruction. However, if the terminal driver does not appear, press <Enter> twice to return to the STAR Main Menu.

At this juncture, select 52 and follow the instructions on how to select a format to identify the terminal driver. If you believe you have entered the terminal driver correctly, press q . If you want to see the list of terminal drivers again, follow the instructions. You are requested to input your terminal driver identification again, and if it is accepted after you input it, then the computer responds "Your Terminal Driver is set to your selection" and you press <Enter> (also referred to as <RETURN>) again. If you want to be sure everything is satisfactory, select 51 to see the name of your terminal driver.

You will not be able to proceed to do a search unless the terminal driver is correctly selected and identified.

After each <Enter>, the STAR Main Menu reappears. At this point you may select 11 to begin your literature search. The STAR Search Screen (Figure 2) will appear and you will begin your search strategy. 


\section{HOW TO SAVE YOUR SEARCH RESULTS}

When you have completed your search and have successfully removed all of the control characters from the search (see Section 3.11), you are ready to download it onto your personal computer. Press <EsC> to return to the command line and type MENU. You are returned to the STAR Main Menu. Select

22 TYPE FILE <Enter>

The response is:

1. Please enter the file to type: SMTH1.TXT

then, you press

2. PgDn

Select A) ASCII, and then type the destination file name. For example, if you want the file to go to disk C, you would type: C: SMTH1.TXT. Press <Enter> twice to start the file transfer. When complete, press

3. $<$ Esc $>$

and the computer responds:

Type CR to return to menu <Enter>

NOTE: If the wrong search is downloaded; press CTRL $\backslash$ to stop the search and return to the STAR Main Menu to repeat 22 TYPE FILE.

\section{HOW TO EXIT FIREDOC and PROCOMM}

If you wish to exit STAR, at the STAR Main Menu, select
1. 31 LOGOUT $<$ Enter > .

You are quickly disconnected from FIREDOC. Now you must exit ProComm Plus.

2. Alt $\mathrm{H}$ (to hang up the telephone)

3. Alt $X$ 
At this point ProComm asks if you want to:

4. $\quad$ EXIT DOS? $(Y / N)$

Press:

5. $\mathrm{Y}<$ Enter $>$

to leave ProComm Plus.

Your file is now in your personal computer and ready for editing and/or printing. 


\section{APPENDIX E: INTERNET PROCEDURES}

PC/TCP Network Software for DOS, Version 2.05 is a communications software. It is available from FTP Software, Inc., 26 Princess Street, Wakefield, MA 01880. Telephone: 508/685-4000.

Prior to entering the database, it is recommended that you use the VT220 terminal emulator and adjust the color pallet to suit your visual needs. We have found that the following combination, white upon black, is very satisfactory and easy to use. To set the colors, you may edit the software to read:

ftp-attr $=0 \times 1 f, 0 \times 0 f, 0 \times 17,0 \times 32,0 \times 43,0 \times 54 \quad$ (note that the first three are the most important parameters)

To access the host computer, telnet to:

129.6.160.7 <Enter> OR firedoc.cfr.nist.gov <Enter>

You are at the Login screen where you type [in lower case character(s)] in your User ID and the Login Password (this will not appear on the screen). After you have successfully logged into STAR with the communications package of your choice, a WARNING announcement appears. After reading it, type the word accepted. The word must be correctly typed to advance, otherwise the computer breaks the connection. If you have correctly typed the word, the STAR Main Menu (Figure 1) will appear.

Before proceeding to do a search, the terminal driver that matches your terminal type as defined in your communications software configuration must be correctly entered. For example, if you have your software configured for a VT100, select number 62 .

If your terminal driver is not listed, there are two options. If 65 is selected, a list of drivers accepted by the server are noted and your terminal type is entered as per the instruction. However, if the terminal driver does not appear, press <Enter> twice to return to the STAR Main Menu. At this juncture, select 52 and follow the instructions on how to select a format to identify the terminal driver. If you believe you have entered the terminal driver correctly, press q . If you want to see the list of terminal drivers again, follow the instructions. You are requested to input your terminal driver identification again, and if it is accepted after you input it, then the computer responds "Your Terminal Driver is set to your selection" and you press <Enter> (also referred to as <Return>) again. If you want to be sure everything is satisfactory, select 51 to see the name of your terminal driver.

You will not be able to proceed to do a search unless the terminal driver is correctly selected and identified. 
After each <Enter>, the STAR Main Menu reappears. At this point you may select 11 to begin your literature search. The STAR Search Screen (Figure 2) will appear and you will begin your search strategy.

\section{HOW TO SAVE YOUR SEARCH RESULTS}

When you have completed your search and have successfully removed all of the control characters from the search (see Section 3.11), you are ready to download it onto your personal computer. Press <Esc> to return to the command line and type MENU . You are returned to the STAR Main Menu. Select

\section{LOGOUT <Enter>}

You have now exited the Internet telnet session. You are at the FTP prompt, and type:

ftp 129.6.160.7 or

ftp firedoc.cfr.nist.gov

Next, the computer requests your FIREDOC ID and password:

userid for logging in on firedoc.cfr.nist.gov (file name) $x x x x x \quad$ <Enter>

password for logging in as $x x x x$ on firedoc.cfr.nist.gov $x x x x x$ <Enter>

At the next prompt, to request the file to be transferred, type

get smth1.txt (the file name from our example)

The computer then requests:

local file (smith1.txt): $\quad$ c:smth1.txt <Enter>

In this example; you requested that the file to go to disk $C$, with its name smth1.txt. The file is transferred to your computer. At the next prompt, to leave the Internet FTP session, type quit or bye.

You are now back at your local system. 
APPENDIX. F: QUICK GUIDE TO GETTING STARTED

\begin{tabular}{|c|c|c|c|}
\hline Screen Prompt & User Response & Brief Explanation & Manual Location \\
\hline Internet Prompt & telnet 129.6.160.7 & $\begin{array}{l}\text { Access the Server } \\
\text { at NIST }\end{array}$ & p.37 \\
\hline Modem Prompt & $\begin{array}{l}\text { (01) } 301 / 948-4997 \\
(01) 301 / 948-4998\end{array}$ & $\begin{array}{l}\text { Access the Server } \\
\text { at NIST }\end{array}$ & p. 33 \\
\hline Login & $x x 0 x x$ & $\begin{array}{l}\text { Enter in lower case } \\
\text { user identifier code }\end{array}$ & p. 3 \\
\hline Password & $x x x x x$ & $\begin{array}{l}\text { Enter in lower case } \\
\text { user password }\end{array}$ & p. 3 \\
\hline Warning & accepted & $\begin{array}{l}\text { Acknowledge War- } \\
\text { ning }\end{array}$ & p. 4 \\
\hline STAR Main Menu & 62 & $\begin{array}{l}\text { Select Terminal } \\
\text { Type (VT100) }\end{array}$ & p. $4-5$ \\
\hline $\begin{array}{l}\text { STAR Search } \\
\text { Screen }\end{array}$ & 11 & $\begin{array}{l}\text { Select Search } \\
\text { Screen }\end{array}$ & p. $4-5$ \\
\hline Search Screen & WOOD OR WATER & $\begin{array}{l}\text { Search FIREDOC } \\
\text { for Words WOOD } \\
\text { or WATER }\end{array}$ & Section 3.1 \\
\hline Search Screen & $\begin{array}{l}\text { OR, AND, NOT, } \\
\text { ADJ }\end{array}$ & Adjust Recall & Section 3.3 \\
\hline Search Screen & TI (or Other Fields) & $\begin{array}{l}\text { Search Only } \\
\text { Words in Title }\end{array}$ & Section 3.2 \\
\hline Search Screen & * (Wildcard) & Truncates Word & Section 3.5 \\
\hline Search Screen & $<$ Esc $>$ & $\begin{array}{l}\text { Goes to Command } \\
\text { Line }\end{array}$ & Section 3.6 \\
\hline Search Screen & $\mathrm{D}$ & Display Search Set & Section $3.9,5.2$ \\
\hline Option Screen & 0 & $\begin{array}{l}\text { Obtain Printed } \\
\text { Copy of Search }\end{array}$ & Section 3.11 \\
\hline
\end{tabular}




\begin{tabular}{||l|l|l|l||}
\hline Search Screen & MENU & $\begin{array}{l}\text { Returns to Star } \\
\text { Main Menu }\end{array}$ & p. 6,19 \\
\hline STAR Main Menu & 41 & $\begin{array}{l}\text { Removes Control } \\
\text { Characters }\end{array}$ & Section 3.11 \\
\hline STAR Main Menu & 22 & $\begin{array}{l}\text { Transfers File to } \\
\text { Local Computer }\end{array}$ & p. 35 \\
\hline STAR Main Menu & 31 & LOGOUT of STAR & p. 35 \\
\hline Blank Screen & $\begin{array}{l}\text { (ProComm Plus) } \\
\text { Alt H } \\
\text { Alt X }\end{array}$ & $\begin{array}{l}\text { Hangs up Modem } \\
\text { Returns to DOS }\end{array}$ & p. 36 \\
\hline Blank Screen & FTP & $\begin{array}{l}\text { Transfers File to } \\
\text { Local Computer }\end{array}$ & p. 38 \\
\hline
\end{tabular}




\begin{tabular}{|c|c|c|c|}
\hline \multirow{3}{*}{$\begin{array}{l}\text { NIST-114 U.S. DEPARTMENT OF COMMERCE } \\
\begin{array}{l}\text { (REV. 6-93) } \\
\text { ADMAN 4.09 }\end{array} \\
\text { MANIONAL INSTITUTE OF STANDARDS AND TECHNOLOGY } \\
\text { MUSCRIPT REVIEW AND APPROVAL }\end{array}$} & \multicolumn{3}{|c|}{ W (ERE USE ONLV } \\
\hline & \multicolumn{2}{|l|}{ ERB CONTROL NUMBER } & DIVSION \\
\hline & \multicolumn{2}{|c|}{$\begin{array}{l}\text { PUBUCATION REPORT NUMBER } \\
\text { NISTIR } 5305\end{array}$} & CATEGORY CODE \\
\hline $\begin{array}{l}\text { NSTRUCTIONS: ATTACH ORIGINAL OF THIS FORM TO ONE (1) COP } \\
\text { THE SECRETARY, APPROPRIATE EDITORIAL REVIEW BOARD. }\end{array}$ & $\begin{array}{l}\text { PUBLCATION DATE } \\
\text { December } 1993\end{array}$ & & ER PRINTED PAGES \\
\hline
\end{tabular}

THE SECRETARY, APPROPRIATE EDITORIAL REVIEW BOARD.

TITLE AND SUBTITLE (CITE IN FULH)

FIREDOC Users Manual, 3rd Edition

\begin{tabular}{|l|l}
\hline ONTRACT OR GRANT NUMBER & TYPE OF REPORT AND/OR PERIOD COVERED
\end{tabular}

AUTHOR(S) (LAST NAME, FIRST INITIAL, SECOND INITLAL)

Jason, Nora $\mathrm{H}$.

$\mid$\begin{tabular}{|c|c|}
\hline$x$ & $\begin{array}{l}\text { NIST/GAMTHERSBURO } \\
\text { NIST/BOULEER } \\
\text { JIL/BOULEER }\end{array}$ \\
\hline
\end{tabular}

TABORATORY AND DIVISION MAMES (FIRST MIST AUTHOR ONLY

Building and Fire Research Laboratory/Fire Safety Engineering Division

DONSORIMG ORGANIZATION MAME AND COMPLETE ADDRESS (STREET, CTTY, STATE, ZIP)

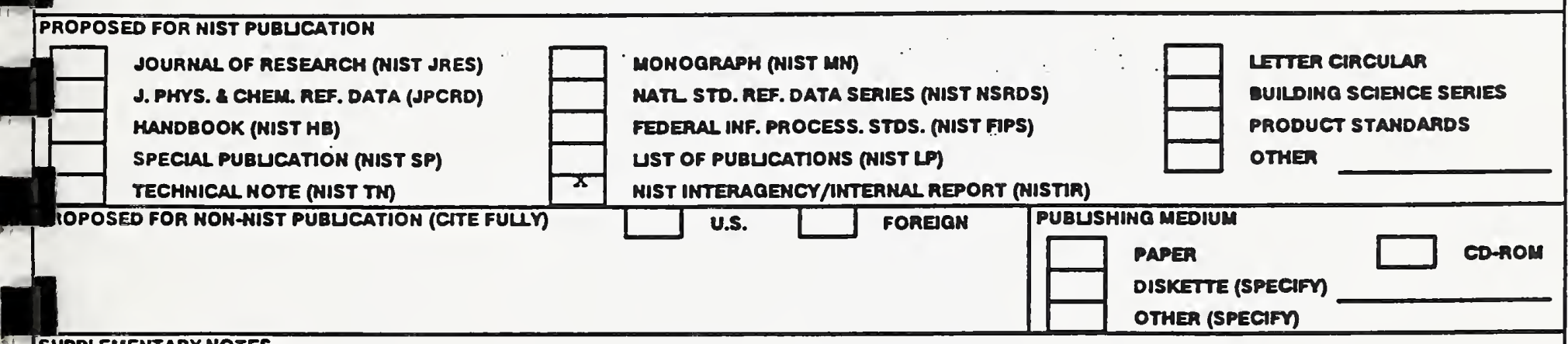

SUPPLEMENTARY NOTES

STRACT (A 2000-CHARACTER OR LESS FACTUAL SUMMARY OF MOST SIGMIFICANT INFORMATION. IF DOCUMENT INCLUDES A SIOMIFICANT BIBUOQRAPHY OR LTERATURE SURVE, CITE IT HERE. SPEL OUT ACRONYMS ON FIRST REFERENCE) (CONTINUE ON SEPARATE PAQE, IF NECESSARY.)

FIREDOC is the :on-line bibliographic database which reflects the holdings (published reports, journal articles, conference proceedings, books, and audiovisual items) of the Fire Research Information Services (FRIS) at the Building and Fire Research Laboratory (BFRL), National Institute of Standards and Technology (NIST). This manual provides step-by-step procedures for entering and exiting the database via telecommunication lines, as well as a number of techniques for searching the database and processing the results of the searches.

This Third Edition is necessitated by the change to a UNIX platform. The new computer allows for faster response time if searching via a modem and, in addition, offers Internet accessibility. FIREDOC may be used with personal computers, using DOS or Windows, or with Macintosh computers and workstations. A new section on how to access Internet is included, and one on how to obtain the references of interest to you. Appendix F: Quick Guide to Getting Started will be useful to both modem and Internet users

WORDS (MAXIMUM OF 9; 28 CHARACTERS AND SPACES EACH; SEPARATE WITH SEMICOLONS; ALPHABETIC ORDER; CAPITALIZE ONLY PROPER MAMES)

latabases; fire engineering; fire research; fire safety; information retrieval; information dissemination; manuals; building technology; building fires; earthquakes

ILABIITTY

$X$ UNUMTED

ORDEA FROM SUPERINTENDENT OF DOCUMENTS, U.S. OPO, WASHINGTON, DC 20402

ORDER FAOM MTIS, SPRIMAFIED, VA 22161
NOTE TO AUTHOR(S): IF YOU DO NOT WISH THIS LANUSCRIPT ANHOUNCED EEFORE PUBUCATIOK, PLEASE CHECK HERE. 

